\title{
Mixing matters
}

\author{
Systematic gathering of detailed demographic data on the workforce is needed to ensure continued progress in \\ diversifying biotech.
}

t he business case for changing the biotech workforce to be more inclusive and diverse is simple. Competitive businesses demand the best use of the talent pool available and the ability to motivate all their employees. They require leadership teams that understand the needs of all the diverse groups that comprise their consumer base. Businesses with workforces that are replete with obvious bias fail to hire the most gifted talent, fail to fully grasp the markets they serve and thus fail to perform optimally as a consequence.

It is time for biotech companies to stop paying lip service to diversity and treating it as a distraction from their day-to-day business. The sector's industry body, the Biotechnology Innovation Organization (BIO), certainly thinks so. BIO's Right Mix Matters campaign, which was launched in April, seeks to spark greater diversity in the upper echelons of the industry, not only of gender, race and sexual identity (LGBTQ+), but also in the representation of a broader set of nationalities.

Although progress is being made, the industry has a long way to go before achieving a diverse workforce.

Since the end of 2015, when this journal last reported on the issue (Nat. Biotechnol. $33,781,2015)$, the proportion of women in senior management teams at the 300 largest (by market capitalization) public biotech companies has grown. According to data from company websites, it has increased from $19.4 \%$ in 2015 to $24.9 \%$ today. Over the same period, participation of women on biotech boards has increased even faster, from $10.8 \%$ to $17.1 \%$. A handful of biotech companies (e.g., Biogen and Genentech) also are funding diversity programs to address the under-representation of minorities in biotech leadership positions (data indicate black people make up $13 \%$ of the US population but hold only $3 \%$ of executive positions; Latina/Latino/Hispanic $18 \%$, but only $4 \%$ of executive positions).

In the intervening time, $\mathrm{BIO}$ has also shifted from being a passive advocate for diversity and inclusion to an active one. For most of its history, BIO seemed to regard women as something of a special interest group-or a rather exotic one-sex nationsetting apart areas of its international hall at the annual convention for independent groups, such as Women in Bio. This changed in February 2016, when it established a Workforce Development, Diversity, and Inclusion Committee to tackle the issue head on. By June 2017, the committee had drawn up a set of principles that BIO itself adopted. Now it is moving from principles to practice, setting diversity targets and putting in place resources to help its member companies move in the right direction.

\section{It is time for biotech}

\section{companies to stop paying lip service to diversity.}

According to Helen Torley, chair of the committee and CEO of San Diego startup Halozyme Therapeutics, BIO wants to dramatically increase diversity (across its many dimensions) and go from the current situation, where women, minorities and LGBTQ people comprise $25 \%$ of biotech company executive teams and $10 \%$ of biotech boards (BIO data), to a scenario in 2025 where the representation of these groups rises to $50 \%$ and $30 \%$, respectively.

Bringing about the change in biotech business and hiring culture will take concerted action. To ensure meaningful progress, industry leaders must continue to make the case that diversification is needed not only in the C-suite, but outside it. Biotech startup culture lies at the intersection of academia and venture capital, two walks of life also dominated by white men. Our data show that public-company scientific and clinical advisory boards are $89 \%$ male. Similarly, Crunchbase reports that $91 \%$ of US-based venture capitalists are men. And data from PitchBook indicate that male startup founders account for $97.8 \%$ of the capital raised across all sectors.

BIO’s Right Mix Matters initiative seeks to address the above problems by putting practical tools in the hands of companies that will make it easier to build more diverse teams. For example, the BIOBoardlist provides a searchable online database containing resumes of diverse candidates that can be used by company search committees seeking to recruit promising talent from a wider base.

Similarly, the Diversity \& Inclusion Toolkit pools a variety of best practices and metrics from successful diversity programs across the sector, together with specific human resources templates for tracking workforce composition, scholarly pieces and training courses on such topics as unconscious bias, mentoring and sponsorship.

Changing hearts and minds in maledominated boardrooms and reminding management teams to keep prioritizing this issue is a matter of social justice, fairness and inclusiveness. But there is also a business case to be made.

Several studies have pointed to the business advantages of a diverse workforce. A 2016 survey by the Peterson Institute for International Economics, which looked at $>21,000$ companies from 91 countries across all industry sectors, suggests that level of diversity correlates with crude measures of company performance, such as revenue generation. In its latest study of $>1,000$ companies in 12 countries, management consultancy McKinsey concludes that companies in the top quartile for leadership diversity are $21 \%$ more likely to outperform on profitability and $27 \%$ more likely to create more value than other companies. Conversely, companies in the bottom quartile for leadership diversity are $29 \%$ less likely to achieve above-average profitability.

Starting to systematically measure, quantify and report the extent of bias in the biotech workforce is critical to continue monitoring progress. In the meantime, biotech boards should follow BIO's lead and start to treat inclusivity as a necessity, rather than a nicety. In the increasingly competitive market for global talent, biotech companies need to create an environment in which they are a place where all that talent in all its diversity can thrive.

Published online: 4 June 2019

https://doi.org/10.1038/s41587-019-0160-9 